\title{
A APROPRIAÇÃO DA ESCRITA ALFABÉTICA DE ALUNOS QUE FREQUENTAM UMA SALA DE APOIO DE LÍNGUA PORTUGUESA NA VISÃO DOS PROFESSORES
}

\author{
Simone BUENO \\ Universidade Estadual de Ponta Grossa
}

RESUMO: Este trabalho é parte integrante de uma pesquisa de mestrado em andamento, cujo objetivo principal é investigar a concepção de alfabetização que manifestam professores que atuam em Salas de Apoio à Aprendizagem de Língua Portuguesa. A entrada de alunos com graves problemas de escrita ortográfica nos anos finais do Ensino Fundamental é um fator de preocupação para os educadores de língua portuguesa. Várias são as razões que justificam tal fato, como, por exemplo, a utilização de métodos de alfabetização que não permitem que os alunos se apropriem totalmente do sistema de escrita alfabética, causando dificuldades na escrita. Embora alguns programas do Governo Federal busquem a formação continuada de professores para que todos os alunos sejam alfabetizados até o $3^{\circ}$ ano do ensino fundamental, como o PNAIC (MEC, 2015), muitos profissionais consideram que a realidade ainda não é essa, o que condiz com os dados levantados pelo IBGE (2010), que apontam um índice de analfabetismo de $9 \%$ no caso de crianças com 10 anos ou mais, mesmo que quase $97 \%$ das que estão na faixa dos 7 aos 14 anos de idade estejam na escola. Para ajudar na superação das dificuldades desses alunos, as escolas públicas do Paraná oferecem a esses alunos o estudo em contraturno nas Salas de Apoio à Aprendizagem. Procurando avaliar essa situação, esse trabalho dará voz a professores para que estes manifestem-se quanto aos critérios nos quais se baseiam para afirmar que um aluno é ou não é alfabetizado. Metodologicamente, a pesquisa é qualitativa e os dados foram obtidos através de dois instrumentos: análise de documentos e entrevistas com docentes. O referencial teórico utilizado baseia-se em autores como Cagliari (2008), Soares (2015) e em normativas específicas, como LDB (1996), Decreto 6094/07 Plano de Metas Compromisso Todos pela Educação (2007), DCE/Língua Portuguesa, (2008) e Instrução $n^{\circ}$ 010/2014- SUED/SEED - Autorização de Salas de Apoio à Aprendizagem (2014).

PALAVRAS-CHAVE: concepção de alfabetização; aquisição da escrita alfabética; Sala de Apoio à Aprendizagem

ABSTRACT: This work is an integral part of an ongoing master's degree research, whose main objective is to investigate the literacy conception manifested by teachers who work in Portuguese Language Learning Support Rooms. The entry of students with severe orthographic writing problems in the final years of Elementary School is a concern for Portuguese-speaking educators. There are several reasons for this, such as the use of literacy methods that do not allow students to take full possession of the written code, causing difficulties in writing. Although some Federal Government programs seek the continuing education of teachers so that all students are literate by the 3rd year of elementary school, for example the PNAIC (MEC, 2015), many professionals consider that this is not yet the case, what is in line with data collected by IBGE (2010), which indicate an illiteracy rate of $9.0 \%$ in the case of children aged 10 years or more, even though almost 97\% of the children in 7-14 age group be at school. To help to overcome the difficulties of these students, the public schools of Parana offer these students extracurricular activities in the Rooms of Support to Learning. In order to assess this situation, this work will give teachers a voice to express their opinion about the criteria on which they are based to affirm that a student is or is not literate. Methodologically, the research is qualitative and data were obtained through two instruments: document analysis and interviews with teachers. The theoretical framework used is based on authors such as Cagliari (2008), Soares (2015) and specific regulations, such as LDB (1996), Decree 6094/07 - Plan of Commitment All for Education (2007), DCE / 
Portuguese Language (2008) and Instruction No. 010/2014 - SUED / SEED - Authorization of Learning Support Rooms (2014).

KEYWORDS: literacy conception; acquisition of alphabetic writing; Learning Support Rooms

\section{Introdução}

Em dez anos de trabalho como professora junto a turmas do $6^{\circ}$ ano, ministrando aulas de Língua Portuguesa em escolas da rede pública, pude observar o aumento no número de alunos que chegavam aos anos finais do Ensino Fundamental ainda sem terem se apropriado completamente do sistema de escrita alfabética, causando preocupação entre os educadores.

Para Soares (2015), é preciso que se diferencie um processo de aquisição da língua de um processo de desenvolvimento da língua. Para a mesma autora, por esse motivo, há que se nomear esses dois processos de forma diferenciada; por isso ao processo de aquisição da escrita alfabética ela dá o nome de alfabetização e ao processo de desenvolvimento da língua atribui o nome letramento.

Sendo assim, podemos constatar que o não domínio do sistema de representação da escrita pelo aluno faz com que ele tenha defasagens na alfabetização.

Embora o Governo Federal tenha implementado o Plano de Metas Compromisso Todos pela Educação, através do Decreto 6094/07 de 24 de abril de 2007 e que este, em seu artigo $2^{\circ}$, inciso II, estabeleça como objetivo "alfabetizar as crianças até, no máximo, oito anos de idade" e que, para esse fim, tenha criado programas de formação continuada para capacitar professores dos anos iniciais do ensino fundamental como Pró-letramento e o PNAIC (Pacto Nacional pela Alfabetização na Idade Certa) não se pode esquecer que alunos continuam chegando ao $6^{\circ}$ ano do ensino fundamental sem se apropriarem do sistema de escrita alfabética, dificultando muito o trabalho nos anos finais do ensino fundamental, não só do professor de Língua Portuguesa, mas também dos professores das outras disciplinas.

(...) nos anos iniciais do século XXI, (...), o fracasso em alfabetização persiste, embora esse fracasso, agora, configure-se de forma diferente: enquanto, no período anterior, o fracasso, revelado por meio sobretudo de avaliações internas à escola, concentrava-se na série inicial do ensino fundamental, a então geralmente chamada "classe de alfabetização", o fracasso na década inicial do século XXI é denunciado por avaliações externas à escola - avaliações estaduais, nacionais e até internacionais -, e já não se concentra na série inicial da escolarização, mas espraia-se ao longo de todo o ensino fundamental, chegando mesmo ao ensino médio, traduzido em altos índices de precário ou nulo domínio da língua escrita, evidenciando grandes contingentes de alunos não alfabetizados ou semialfabetizados depois de quatro, seis, oito anos de escolarização." (SOARES, 2016, p. 23 24)

Galvão e Leal também são autoras que procuram demonstrar que a alfabetização não tem se efetivado como preveem os documentos.

O que temos, nos dias atuais no nosso país, segundo recentes avaliações, são patamares inaceitáveis de analfabetismo, e o que é mais grave, alunos saídos do nosso sistema de ensino e que, no entanto, não conseguem ler e escrever um texto simples após quatro ou cinco anos de escolaridade! (GALVÃO, LEAL, 2005, p.12)

A constatação das autoras citadas é facilmente verificada através de resultados estatisticamente comprovados pelo IBGE e INEP, nos quais é possível verificar as defasagens relativas principalmente a alunos do $6^{\circ}$ ano. 
Segundo dados levantados pelo IBGE (2010) a taxa de analfabetismo é de 9\% no caso de crianças com 10 anos ou mais, embora quase 97\% das que estão na faixa dos 7 aos 14 anos de idade estejam na escola. Outro dado relevante é a taxa de reprovação por série (IBGE, 2010) que aponta $15,2 \%$ para alunos do $6^{\circ}$ ano, é o maior índice de reprovação dos anos finais do ensino fundamental.

Dados mais recentes do INEP (2014) também demonstram que o $6^{\circ}$ ano é o mais problemático do ensino fundamental em relação à distorção série/idade com 30,7\% e o que tem a taxa de aprovação mais baixa com $81,6 \%$.

Como forma de garantir que alunos tenham oportunidade de superar suas dificuldades, foi implantado no Paraná, em 24 de março de 2004, pela Resolução Secretarial de nº 298/04 e da Instrução Conjunta $n^{\circ}$ 04/04 SEED/SUED/DEF, regulamentado por meio da Resolução 2772/2011, o ensino extracurricular em contraturno por meio das Salas de Apoio à Aprendizagem (RIBEIRO, 2013).

Mais tarde, a Instrução $n^{\circ}$ 010/2014, de 08 de dezembro de 2014 prevê a abertura das Salas de Apoio para o ano de 2015, com os seguintes objetivos:

... devem ser constituídas para a ação pedagógica de enfrentamento das dificuldades de Língua Portuguesa e Matemática dos alunos matriculados no Ensino Fundamental, anos finais $\left(6^{\circ}\right.$ e $7^{\circ}$ anos), no que se refere aos conteúdos básicos dessas disciplinas dos anos anteriores ao ano no qual os alunos se encontram matriculados (PARANÁ, 2014)

Dessa forma, o aluno que ingressa nos anos finais do ensino fundamental na rede estadual paranaense sem estar efetivamente alfabetizado terá possibilidade de se apropriar do sistema de representação da escrita. Mas para que isso ocorra é preciso que o professor consiga diagnosticar quais são as verdadeiras dificuldades de seus alunos, é preciso que ele tenha clareza sobre o que de fato acontece - se o aluno é realmente analfabeto ou se tem lacunas que podem ser resolvidas e, a partir daí, planeje ações que visem à apropriação do sistema de escrita.

Sendo assim, esse trabalho tem como principal objetivo analisar a concepção de alfabetização de um professor que trabalha com a sala de apoio de uma escola pública de Ponta Grossa - PR, procurando observar quais critérios utiliza como diagnóstico e que encaminhamentos considera pertinentes para a superação das dificuldades de seus alunos.

\section{Metodologia, contexto e perfil do entrevistado}

A proposta metodológica que norteou o presente trabalho foi a qualitativa. Segundo Flick (2013, p. 23), a vantagem desse tipo de pesquisa é que "a análise detalhada e exata de alguns casos pode ser produzida, e os participantes têm muito mais liberdade para determinar o que é importante para eles e para apresentá-los em seus contextos".

A coleta de dados se fez através de entrevista semiestruturada que, segundo Lüdke e André (2015), é a mais adequada para a pesquisa em educação por ter um estilo mais livre.

Ainda segundo as autoras há um benefício da entrevista em relação a outros métodos de pesquisa quando o assunto faz parte do cotidiano do entrevistado.

[...] tratando-se de pesquisa sobre o ensino, a escola e seus problemas [...], enfim, toda essa vasta rede de assuntos que entram no dia a dia do sistema escolar, podemos estar seguros de que, ao entrevistarmos professores [...] não lhes estaremos certamente impondo uma problemática estranha, mas, ao contrário, tratando com eles de assuntos que lhes são muito familiares sobre os quais discorrerão com facilidade. (LÜDKE, ANDRÉ, 2015, p. 41-42) 
Os dados obtidos foram expostos a uma análise interpretativa, conforme explica Flick (2013, p.148), nesse tipo de método "a interpretação remete imediatamente aos dados e é a análise em si”.

A pesquisa foi realizada em uma escola da rede pública de Ponta Grossa - PR que atende alunos do $6^{\circ}$ ao $9^{\circ}$ ano do ensino fundamental e que possui quatro turmas de $6^{\circ}$ ano no turno vespertino. Como a instrução 022/2008 SUED/SEED prevê a abertura de uma turma de apoio para cada três turmas de $6^{\circ}$ ano, a escola conta com uma Sala de Apoio de Língua Portuguesa que funciona em contraturno, atendendo a 20 alunos.

É importante salientar que há uma troca de alunos durante os bimestres que obedece a alguns critérios previamente definidos pela Secretaria de Educação como superação das dificuldades, não frequência; portanto, ao longo do ano, o número de alunos que passará pela Sala de Apoio dependerá dessa rotatividade.

Antes da exposição e análise da entrevista, é importante traçarmos um breve perfil do professor entrevistado para uma melhor compreensão dos dados.

O professor trabalha há quinze anos na rede estadual de ensino e pertence ao quadro próprio do magistério. Tem formação profissional como docente (antigo magistério) e licenciatura em letras - português e espanhol, mas nunca trabalhou com os anos iniciais do ensino fundamental.

$\mathrm{Na}$ escola em que trabalha atualmente, atua há cinco anos e é o terceiro ano que trabalha com uma turma de Sala de Apoio, porém é a primeira vez nessa escola.

Também é necessário destacar o fato de que é o segundo professor a trabalhar com a turma. A mudança aconteceu ainda na metade do $1^{\circ}$ bimestre. A entrevista foi concedida durante o $2^{\circ}$ bimestre de 2016.

\section{Concepção de alfabetização e o trabalho nas Salas de Apoio}

O roteiro da entrevista teve como temas principais a alfabetização e o trabalho específico com as Salas de Apoio à Aprendizagem.

\section{PESQUISADORA: O que entende por alfabetização?}

PROFESSOR: Alfabetizar não é apenas ensinar a ler e escrever, mas sim apropriar-se da leitura e fazer uso dessas habilidades nas suas práticas sociais. Considero que alfabetizar é a relação entre aluno e seu conhecimento de mundo.

Ao analisar essa primeira concepção de alfabetização, apontada pelo professor, é possível perceber que ele traz a noção de alfabetização atrelada ao conceito de letramento. Porém, é preciso estar atento, pois "se a alfabetização é uma parte constituinte da prática da leitura e da escrita, ela tem uma especificidade, que não pode ser desprezada" (SOARES, 2003, p.16).

Essa especificidade apontada por Soares (2003) diz respeito à própria aquisição do sistema de escrita alfabética por meio de atividades sistematizadas.

Segundo Galvão e Leal (2005, p. 17) “o ensino sistemático do sistema alfabético é não só desejável como também necessário".

Ao caracterizar a alfabetização como parte do processo de letramento corre-se o risco de acreditar que ela é um processo natural que acontecerá pelo simples fato de se estar inserido dentro de práticas sociais que envolvem a escrita.

[...] com a hegemonia do discurso do letramento, muitos estudiosos de linguística e de didática da língua, em nosso país, passaram a apostar numa aprendizagem espontânea da escrita alfabética, que supostamente resultaria do mero fato das crianças estarem expostas a situações onde se lessem e escrevessem os textos do mundo real. (MORAIS, 2006, p. 4) 
Soares (2003) acredita que um dos responsáveis pela precariedade do domínio da leitura e da escrita pelos alunos é a diluição da alfabetização nas práticas de letramento.

Albuquerque e Morais (2005) apontam que essa preocupação é visível inclusive na produção de materiais didáticos.

...os autores dos atuais livros didáticos de alfabetização parecem estar mais preocupados com o eixo do letramento (diversidade e representatividade do repertório textual, natureza e diversidade das práticas de leitura e produção textual) e, no que diz respeito à apropriação do SEA, têm deixado a desejar tanto em relação ao número de atividades quanto à natureza delas. (ALBUQUERQUE, MORAIS, 2005, p. 157)

Cagliari (2008) aponta que é papel da escola inserir a criança em novos usos da linguagem e, embora se refira a crianças que iniciam no processo de alfabetização, sua fala é pertinente para o trabalho com alunos que ainda não se apropriaram do sistema de escrita alfabética.

A criança que se inicia na alfabetização já é um falante capaz de entender e falar a língua portuguesa com desembaraço e precisão nas circunstâncias de sua vida em que precisa usar a linguagem. Mas não sabe escrever nem ler. Esses são usos novos da linguagem para ela, e é sobretudo isso que ela espera da escola. (CAGLIARI, 2008, p. 29)

(2) PESQUISADORA: Em sua turma há alunos que você considera estarem defasados no que se refere à alfabetização?

PROFESSOR: Sim, considero que a maioria dos alunos que frequenta (referindo-se à Sala de Apoio) possui defasagem na alfabetização.

PESQUISADORA: Que defasagens seriam essas?

PROFESSOR: Dificuldades de leitura e escrita, na interpretação, na organização de ideias, produção textual.

A relação de defasagens que o professor menciona reitera sua crença de que a alfabetização e o letramento se fundem. Aqui não fica claro se realmente seus alunos possuem defasagens na alfabetização ou apresentam lacunas próprias da faixa etária que se encontram, já que mesmo alunos alfabetizados podem apresentar dificuldades na interpretação de determinados tipos de textos, na organização de ideias e mesmo na produção textual.

Apesar disso, no trabalho em sala de aula observa-se que o professor faz atividades especificas voltadas para a aquisição do sistema de escrita.

(3) PESQUISADORA: Como você trabalha com os alunos da Sala de Apoio? Há um planejamento específico para sanar dificuldades ligadas à alfabetização?

PROFESSOR: Sim. Através de jogos lúdicos, percebi o quanto esse recurso é motivador. O bingo ortográfico é um dos materiais que utilizo, pois o aluno precisa refletir sobre os sons e não apenas os significados das palavras. Outro jogo é para formar o maior número de palavras e através das palavras podemos explorar a construção de frases e textos.

O professor aproveita para mostrar o caderno de seus alunos onde é possível perceber atividades sistematizadas para aquisição do sistema de escrita, são exercícios sobre dificuldades ortográficas, famílias silábicas, relação grafema/fonema. 
Quando indagado sobre onde busca os materiais para seu trabalho a resposta é bastante significativa.

(4) PROFESSOR: Eu encontro na apostila e cadernos dos filhos, materiais do primeiro ao quinto ano e também na internet.

PESQUISADORA: E as formações específicas promovidas pelo NRE/SEED, há alguma referência à alfabetização?

PROFESSOR: Quando participei, eram poucas reuniões, uma por semestre. Não há formação para alfabetização. O que tem são sugestões de materiais, atividades para serem trabalhadas durante as aulas.

O professor dá a entender que as atividades são bem gerais, não há ainda um encaminhamento nesse sentido. Não tendo esse respaldo, é natural que o professor busque alternativas para preparar sua aula. Dessa forma, é perfeitamente compreensível que o professor lance mão do que está ao seu alcance, se seus filhos estão alfabetizados acreditará que os materiais que foram utilizados para alfabetizá-los são eficazes. Embora isso, na prática, não seja concretizado tão facilmente.

Apesar de ainda não disponibilizar um material didático atualizado que norteie o trabalho do professor, os únicos livros didáticos produzidos têm mais de dez anos, algumas reformulações significativas foram feitas nos últimos anos, uma delas se relaciona à ficha de encaminhamento preenchida pelos professores regentes dos sextos anos e que serve de ponto de partida no trabalho realizado pelos professores da Sala de Apoio.

Até 2014 essa ficha era separada em três grandes eixos: oralidade, leitura e escrita. A escrita, que é o eixo que se relaciona diretamente com o tema desse trabalho, a alfabetização, era subdividida em sete aspectos a serem avaliados pelos professores: escrever com clareza, coerência e utilizando as regras ortográficas; ter noções básicas de utilização dos sinais de pontuação; ter noções básicas de acentuação; reconhecer maiúsculas e minúsculas, empregando-as na escrita; fazer concordância verbal e nominal; utilizar adequadamente os elementos coesivos (pronomes, adjetivos, conjunções,...) substituindo palavras repetidas no texto.

Em 2015 essa ficha sofreu uma reformulação e a escrita separou-se em dois eixos distintos: apropriação do sistema da escrita e prática discursiva da escrita. ${ }^{1}$

O eixo que agora tratava de questões específicas da alfabetização era denominado "apropriação do sistema da escrita", o que se pode interpretar como uma preocupação com a demanda de alunos que ingressava na Sala de Apoio trazendo dificuldades específicas relacionadas ao processo de aquisição do sistema de escrita alfabética.

Esse novo eixo contempla os seguintes conteúdos: compreensão das diferenças existentes entre os sinais de sistema de escrita e outras formas e sistemas de representação; reconhecimento do alfabeto e dos diferentes tipos de letras; percepção da segmentação das palavras na escrita; reconhecimento sobre as especificidades da ortografia das palavras com estruturas silábicas mais frequentes (CV, V, CCV e CVC); compreensão sobre a relação entre letras e fonemas; constituição escrita das palavras (compreensão das sílabas); reconhecimento da existência das palavras em textos; a tonicidade e elementos notacionais na escrita das palavras.

Embora essa mudança tenha sido significativa, ainda não há um consenso no modo como a ficha de encaminhamento é preenchida.

\footnotetext{
1 Embora os eixos de leitura e oralidade também tenham sofrido alterações, elas foram menores. Os eixos passaram a se denominar "prática discursiva da leitura" e "prática discursiva da oralidade" e tiveram pequenas mudanças em seu conteúdo.
} 
(5) PESQUISADORA: Você considera claros os critérios para o encaminhamento de um aluno para a Sala de Apoio?

PROFESSOR: Não. Essa ficha precisa ser reelaborada para atender a clientela inserida no programa. Outra questão é no início do ano letivo, o professor regente precisa preencher essas fichas sem ao menos conhecer o aluno. É necessário um período de convivência para depois diagnosticar suas defasagens.

Nesse mesmo sentido Nogueira (2015), fazendo um estudo sobre a ficha de encaminhamento de alunos para as Salas de Recursos Multifuncional, cuja ficha também é preenchida por professores de Língua Portuguesa logo no início do ano, também aponta essa dificuldade dos professores em diagnosticarem o estágio em que seus alunos se encontram.

[...] não é concebível que essa ficha seja preenchida logo após a primeira produção de texto de um aluno do $6^{\circ}$ ano, que ingressa na escola no início do ano letivo. É preciso tempo para que o professor conheça o aluno e proponha um trabalho responsável com a escrita da parte do professor que é especialista na área da linguagem. (NOGUEIRA, 2015, p. 82)

O professor também foi indagado sobre como era sua comunicação com o professor regente, relação essencial para o processo de superação das dificuldades por parte do aluno, conforme consta nas atribuições para o professor da Sala de Apoio na Instrução nº 010/2014.

a) elaborar o Plano de Trabalho Docente juntamente com a equipe pedagógica, professores regentes, de acordo com o Projeto PolíticoPedagógico para Língua Portuguesa e Matemática, com atividades e metodologias adequadas para a superação das dificuldades referentes aos anos anteriores em que o aluno está matriculado;

[...]

f) decidir, com a equipe pedagógica e os professores regentes, a permanência ou a dispensa dos alunos das Salas de Apoio à Aprendizagem, após a frequência mínima de um período de avaliações... (PARANÁ, 2014, p. 6, 7).

E também nas atribuições para professor regente.

[...]

c) participar, com a equipe pedagógica e o professor da Sala de Apoio à Aprendizagem, da definição de ações pedagógicas que possibilitem a superação das dificuldades apresentadas pelos alunos;

d) realizar um trabalho conjunto com o professor da Sala de Apoio para acompanhar a evolução da aprendizagem do aluno, bem como assegurando que haja um diagnóstico contínuo sobre a produção dos alunos dispensados. (PARANÁ, 2014, p. 5, 6)

(6) PESQUISADORA: Como é sua comunicação com o professor regente, há um trabalho em conjunto?

PROFESSOR: Por trabalhar na escola nos dois turnos, consigo trocar ideias com os professores regentes. Mas já houve escolas que trabalhei só com a Sala de Apoio, daí ficava mais difícil o contato.

A situação vivenciada pelo professor é a ideal para que o trabalho na Sala de Apoio à Aprendizagem produza resultados, a conversa e o trabalho em conjunto são vitais para que o aluno consiga superar suas dificuldades. Sem essa comunicação, corre-se o risco de que cada 
professor trace objetivos e percorra caminhos diferentes o que, ao invés de contribuir, acabará dificultando ainda mais a superação das defasagens apresentadas pelos alunos.

$\mathrm{Na}$ verdade, no que diz respeito à aprendizagem de leitura e escrita, todos os professores têm sua parcela de responsabilidade. Esses eixos não deveriam ficar somente sob a responsabilidade do professor de Língua Portuguesa, já que todas as disciplinas necessitam de alunos que tenham o mínimo domínio do sistema de escrita alfabética.

[...] decorre que o ensino e a aprendizagem da leitura e da escrita fazem parte das atividades de todas as disciplinas (donde decorre o caráter evidentemente transdisciplinar dessa aprendizagem). Deve-se propor ao educando não apenas a informação, mas sua busca através do texto escrito. A própria atividade de organização do conhecimento deve ser escrita, cabendo aos professores de todas as disciplinas o trabalho sistemático com a leitura e a redação. (BRITTO, 2009, p.25)

\section{Considerações finais}

Embora este trabalho seja um estudo inicial sobre a concepção de alfabetização manifestada por professores que atuam nas Salas de Apoio à Aprendizagem de Língua Portuguesa, alguns importantes apontamentos podem ser feitos a partir da análise da fala do professor.

O primeiro deles é que ainda não está clara a especificidade da alfabetização, pois ela continua sendo (con)fundida com/ao letramento. Dessa forma, se os professores que recebem alunos com dificuldades específicas relacionadas ao sistema de escrita não traçarem um planejamento sistematizado para superação dessas dificuldades possivelmente os resultados continuarão sendo os mesmos que se veem nas estatísticas levantadas: o $6^{\circ}$ ano continuará sendo a etapa escolar em que mais se reprova e que mais agrega alunos com distorção idade/série.

Em segundo lugar, elenca-se a necessidade de revisão relacionada ao encaminhamento de alunos direcionados às Salas de Apoio, o professor precisa ter um mínimo de condições para diagnosticar com responsabilidade quais são as reais necessidades de seus alunos, e não fazer isso de maneira atropelada por conta de prazos pré-estabelecidos.

Por fim, há a necessidade de se rever a formação continuada que recebem professores de $6^{\circ}$ ano. Essas formações precisam contemplar a alfabetização como um problema que atinge os anos finais do ensino fundamental. Só assim será possível pensar na melhoria da qualidade da educação básica.

\section{Referências}

ALBUQUERQUE, Eliana Borges C. de; MORAIS, Artur Gomes. O livro didático de alfabetização: mudanças e perspectivas de trabalho. In: MORAIS, Artur Gomes; ALBUQUERQUE, Eliane Borges C. de; LEAL, Telma Ferraz (orgs). In: Alfabetização: apropriação do sistema de escrita alfabética. Belo Horizonte: Autêntica, 2005. p. 147-166.

BRITTO, Luiz Percival L. Educação linguística escolar: para além das obviedades. In: CORREA. Djane Antonucci. SALEH, Pascoalina Bailon de Oliveira. (Org.). Estudos da linguagem e currículo de Letras: diálogos (im)possíveis. Ponta Grossa: EDUEPG, 2009.

BRASIL. Decreto 6094/07. Plano de Metas Compromisso Todos pela Educação - 2007. Disponível em 〈http://presrepublica.jusbrasil.com.br/legislacao/94807/decreto-6094-07> Acesso em fevereiro de 2016. 
CAGLIARI, Luiz Carlos. Alfabetização e Linguística. 10. ed. São Paulo: Scipione, 2008.

FLICK, Uwe. Introdução à Metodologia de Pesquisa: um guia para iniciantes. São Paulo: Penso Editora, 2013.

GALVÃO, Andréa; LEAL, Telma Ferraz. Há lugar ainda para métodos de alfabetização? Conversa com professores (as). In: MORAIS, Artur Gomes; ALBUQUERQUE, Eliane Borges C. de; LEAL, Telma Ferraz (orgs). In: Alfabetização: apropriação do sistema de escrita alfabética. Belo Horizonte: Autêntica, 2005. p. 12-28.

IBGE. 7 a 12: Vamos conhecer o Brasil, 2010. Disponível em: $<$ http://7a12.ibge.gov.br/vamos-conhecer-o-brasil/nosso-povo/educacao.html $>$ Acesso em 21/06/2016.

Reprovação por série: ensino fundamental de 8 e 9 anos (série nova), 2010. Disponível em: $<$ http://seriesestatisticas.ibge.gov.br/series.aspx?no=4\&op=0\&vcodigo=SEE31\&t=reprovacao -serie-ensino-fundamental-8-9> Acesso em 21/06/2016.

INEP. Indicadores $\quad$ Educacionais, 2014. Disponível em: <http://portal.inep.gov.br/indicadores-educacionais>. Acesso em 21/06/2016.

LÜDKE, Menga; ANDRÉ, Marli, E.D.A. Pesquisa em educação: abordagens qualitativas. 2.ed. Rio de Janeiro: E.P.U., 2015.

MORAIS, Artur Gomes de. Concepções e metodologias de alfabetização: por que é preciso ir além da discussão sobre velhos métodos? MEC, 2006. Disponível em $<$ http://portal.mec.gov.br/seb/arquivos/pdf/Ensfund/alf_moarisconcpmetodalf.pdf> Acesso em maio/2016.

NOGUEIRA, Amarili S. Sala de recursos multifuncional e representação da escrita: análise da resolução 13/2007, normativa 16/2011 e ficha de referência pedagógica. $106 \mathrm{f}$. Dissertação. (Mestrado em Linguagem, identidade e subjetividade). UEPG: Ponta Grossa, 2015. Disponível em < http://bicen-tede.uepg.br/tde_busca/arquivo.php?codArquivo=1438> Acesso em 21/06/2016.

PARANÁ. 2008. Instrução 022/2008 - SUED/SEED. Critérios para a abertura da demanda de horas-aula, do suprimento e das atribuições dos profissionais das Salas de Apoio à Aprendizagem - $5^{\mathbf{a}}$ série do Ensino Fundamental da Rede Pública Estadual. Paraná, 2008. Disponível em http://www.educacao.pr.gov.br/arquivos/File/coletaneas/coletanea2008.pdf $>$ Acesso em 21/06/2016.

2014 Instrução no 010/2014- SUED/SEED. Autorização de Salas de Apoio à Aprendizagem. $\quad$ Paraná, 2014. Disponível em <http://www.educacao.pr.gov.br/arquivos/File/instrucoes2014\%20sued\%20seed/instrucao102 014seedsued.pdf $>$ Acesso em 21/06/2016

RIBEIRO, Márcia Vieira. A importância da sala de apoio na aprendizagem: um olhar docente. 35 f. Monografia (Especialização em Educação: Métodos e Técnicas de Ensino). UTFPR:

Medianeira,

2013.

Disponível

em 
http://repositorio.roca.utfpr.edu.br/jspui/bitstream/1/4410/1/md_edumte_2014_2_60.pdf Acesso em fevereiro de 2016.

SOARES, Magda. A reinvenção da alfabetização. 2003. Disponível em < http://pacto.mec.gov.br/images/pdf/Formacao/a-reivencao-alfabetizacao.pdf $>$ Acesso em 21/06/2016.

. Alfabetização e Letramento. 6.ed. São Paulo: Contexto, 2015.

. Alfabetização: a questão dos métodos. São Paulo: Contexto, 2016. 
